\title{
Dossiê
}

Resumo

O interesse e a preocupação em relação ao uso de dispositivos tecnológicos pelos adolescentes têm se acentuado a cada dia. As redes sociais da internet têm sido utilizadas pelos jovens não só para a comunicação, mas também para a segregação social. Este trabalho apresenta uma reflexão sobre uma pesquisa e intervenção realizadas em uma escola pública que teve como tema o uso das redes sociais pelos jovens. Para tanto, utilizou-se a metodologia de conversação de orientação psicanalítica com quatro grupos de adolescentes. Depreendeu-se um processo próprio a cada grupo, além de efeitos das conversações sobre cada sujeito.

Descritores: adolescente; redes sociais; escola.

\section{PSICANÁLISE, EDUCAÇÃO E REDES SOCIAIS VIRTUAIS: ESCUTANDO OS ADOLESCENTES NA ESCOLA}

\author{
Nádia Laguárdia de Lima \\ Nayara Serrano Barcelos \\ Juliana Tassara Berni \\ Karina de Almeida Casula \\ Luiza Pinheiro Mendes Ferreira \\ Ellen Rose Fernandes Figueiredo \\ Karina Nihari Maciel \\ Mirella César Ferraz Nunes \\ Marina Soares Otoni
}

DOI: http://dxdoi.org/10.11606/issn.1981-1624.v20i3p421-440.

Pós-doutoranda pelo programa de pós-graduação em teoria psicanalítica pela Universidade Federal do Rio de Janeiro. Professora do Departamento de Psicologia da Universidade Federal de Minas Gerais, Belo Horizonte, MG, Brasil.

- araduanda em Psicologia pela Universidade Federal de Minas Gerais, Belo Horizonte, MG, Brasil. - n - Psicanalista e psicóloga clínica. Mestranda pela Universidade Federal de Minas Gerais, Belo Horizonte, MG, Brasil

- " . Psicanalista e psicóloga pela Universidade Federal de Minas Gerais, Belo Horizonte, MG, Brasil.

" a n a Graduada em Pedagogia pela Faculdade de Educação da Universidade Federal de Minas Gerais. Mestranda em Psicologia pela Universidade Federal de Minas Gerais, Belo Horizonte, MG, Brasil.

" a m a " Psicóloga. Mestranda em Educação pela Faculdade de Educação da Universidade Federal de Minas Gerais, Belo Horizonte, MG, Brasil.

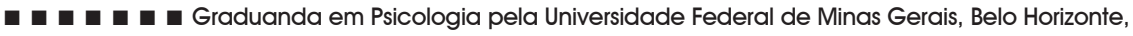
MG, Brasil.

a a a Graduanda em Psicologia pela Universidade Federal de Minas Gerais, Belo Horizonte, MG, Brasil.

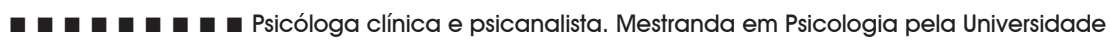
Federal de Minas Gerais, Belo Horizonte, MG, Brasil. 


\section{Introdução}

$\mathbb{E}_{4}$ ste artigo apresenta uma reflexão teórica sobre um trabalho realizado com adolescentes em uma escola pública. A demanda da escola surgiu em função dos problemas advindos do uso excessivo e inadequado das redes sociais da internet pelos adolescentes, em especial a publicação de palavras ofensivas dirigidas aos colegas e fotos constrangedoras de professores e alunos no ambiente escolar.

As redes sociais têm se constituído num desafio para a nossa sociedade, pois elas se infiltram em todos os segmentos da vida humana, como o espaço familiar, educacional, social e político. Elas têm sido utilizadas pelos jovens para a socialização, comunicação e acesso à informação, mas também para a prática de violência e segregação social. A expansão dos aparelhos digitais, que concentram cada vez mais funções e atrativos, coincide com o crescimento das adicções virtuais.

Pais e professores se queixam de perder o controle diante dos alunos que não se desconectam de seus gadgets. Por vezes, as medidas adotadas pela escola estão voltadas apenas para o reforço do controle, como a proibição do uso dos aparelhos celulares em seu espaço físico. Ao buscar erradicar o gozo, a escola obtém como resposta a sua irrupção, muitas vezes de forma drástica. Com efeito, apesar da proibição do uso do celular na escola, os alunos continuam utilizando intensamente os seus celulares em sala de aula e nos diversos ambientes da instituição.

Na puberdade, o sujeito é despertado pelo real do sexo, diante da impossibilidade de responder aos enigmas da vida, da morte e do sexo. Consideramos a adolescência um tempo lógico, de formulação de uma resposta a esse não saber. A atualidade, marcada pelo declínio do Ideal e pela ascensão do objeto a, tem como efeitos a multiplicação de ofertas de identificação e a imposição de modos de gozo comuns a todos. Quais as respostas dos sujeitos adolescentes ao confronto com o real do sexo e aos impasses colocados pela nossa cultura? Como os adolescentes se servem dos dispositivos tecnológicos na atualidade? 


\section{A metodologia de trabalho}

Elaboramos um projeto de pesquisa e intervenção utilizando a metodologia de conversação de orientação psicanalítica lacaniana, um dispositivo clínico elaborado por Miller (2010) apoiado pela ética do desejo e da responsabilização, que permite a atuação do psicanalista nas escolas, como demonstram Lacadèe (2000) e Santiago (2008). Orientados por uma escuta do inconsciente, buscamos dar a palavra aos adolescentes, para conhecer o uso que eles fazem das redes sociais e os impasses que vivenciam nas relações com o Outro por meio das tecnologias digitais.

Buscamos localizar o ponto de mal-estar, próprio a cada sujeito, no seu uso das redes sociais virtuais. Acreditamos que isso revela algo da sua subjetividade, da sua forma de se relacionar com o Outro e do seu modo de gozo.

Aquele que conduz as conversações opera a partir do não saber, provocando a fala do outro e permitindo que emerjam os significantes privilegiados em seus discursos. A transferência, como um laço ao significante, ocupa um lugar fundamental no trabalho de conversação. O deslizamento dos significantes na associação livre e coletiva permite desfazer identificações alienantes, abrindo possibilidades de novas identificações. Cada grupo foi conduzido por um aluno de mestrado, acompanhado por um aluno de graduação que fez o registro e gravou as falas. Quatro grupos de adolescentes, com idade entre onze e dezesseis anos, participaram das conversações. A escola formou os grupos e estabeleceu os horários e os locais para as conversações, mas cada adolescente foi convidado a participar, e teve a liberdade de mudar de grupo. Constatamos que 
cada grupo se constituiu a partir de um significante que conferia aos seus membros uma "identidade imaginária”, mas as conversações permitiram que essa identificação fosse relativizada ou desfeita.

\section{Resultados}

Localizamos um percurso próprio a cada grupo, que assim nomeamos: Grupo 1: da imagem à palavra; Grupo 2: das atuações à palavra; Grupo 3: do discurso do Outro à tomada da palavra e Grupo 4: da segregação à aceitação da diferença.

As discussões teóricas desenvolvidas para a leitura do processo de cada grupo privilegiaram os seguintes temas: a imagem, o ato, o desligamento da autoridade dos pais e a segregação referida à adolescência e à contemporaneidade.

\section{Grupo 1: da imagem à palavra}

Esse grupo foi formado por seis meninas com idade entre quatorze e quinze anos. Logo de início, as adolescentes enfatizaram a falta de um espaço para a palavra na escola. Sobre o uso dos celulares, uma adolescente disse "Gosto muito do meu celular, ele é minha vida, tenho afeto por ele". Quando indagada sobre o motivo dessa relação intensa com o celular, outra participante responde prontamente: "Ele escuta todas as nossas conversas e não conta para ninguém! ".

As poucas chances de diálogo entre as adolescentes na escola, segundo elas, são tratadas pelos professores com punições, como ir à sala da coordenação ou da psicologia. Os comportamentos considerados indesejáveis pela escola, como utilizar o celular durante as aulas e enfrentar os professores, são muito comuns entre algumas alunas desse grupo. Consideramos que

ao manter o aluno na posição de objeto, o que a escola obtém como resposta é a violência. O aumento do "controle" nas escolas visa reforçar o poder quando a autoridade falha. No entanto, ele não consegue silenciar os sujeitos, que insistem em "ser ouvidos" através de seus sintomas escolares. Só a escuta da singularidade pode oferecer uma resposta ao fracasso da educação escolar" (Lima \& Rezende, 2013).

A característica mais marcante do grupo foi a forte presença das fotos pessoais nas conversações. As adolescentes se mostravam por 
meio de fotografias nas redes sociais, e destacavam as possibilidades de transformar a imagem de seus corpos com aplicativos de celulares. A maioria das meninas utilizava os celulares para navegar nas redes sociais e para mostrar as fotografias umas das outras, sempre pontuando as imperfeições ou as perfeições em seus corpos, demonstrando grande insatisfação com o próprio corpo. Elas afirmavam utilizar programas de manipulação de imagem como o Photoshop e outros truques para modificar o corpo e "parecerem mais gostosas". "É para ganhar mais curtidas! " - as curtidas são uma espécie de aprovação social, e, segundo elas, levam ao alcance da fama na internet.

O espaço virtual, em especial as redes sociais, veicula imperativos de beleza e de felicidade que se constituem como requisitos para que o sujeito se apresente na internet. A fotografia é um veículo de apresentação pessoal e de projeção no espaço virtual. O corpo, por meio da foto, passa a ser um suporte de valor no qual a moeda é a curtida. Segundo Le Breton (2003), o corpo na contemporaneidade é um acessório que marca a presença do sujeito, podendo ser modelado e redefinido de acordo com o design do momento.

Uma participante da conversação mostra em seu celular a quantidade de fotos pessoais que possui - "tenho mais de cento e uma fotos" -, e explica que precisa tirar muitas fotos antes de escolher uma para postar na rede: "Tem que ser a foto perfeita!" Essa foto "perfeita", obtida por meio de aplicativos, substitui as intervenções no corpo real, como diz uma adolescente: "Como eu não tenho dinheiro para fazer plástica e nem tempo para ir à academia, eu uso os aplicativos para ter mais bunda, seios maiores e uma cintura fina, além de tirar as espinhas".

A internet fornece para essas adolescentes instrumentos virtuais para a fabricação de uma imagem de corpo perfeito, para ser exibido e curtido pela comunidade virtual. Uma delas comenta:

Uma vez marquei de encontrar com um menino que eu conheci na internet. Eu avisei que pessoalmente eu era muito diferente. Falei várias vezes para ele. Quando ele foi me encontrar eu fiquei dando umas voltas perto de onde ele 
estava, sem saber se eu ia lá falar com ele ou não... Aí quando eu cheguei perto dele, a primeira coisa que ele falou foi "nossa, como você é diferente!".

Consideramos que a imagem do corpo em transformação na puberdade se torna estranha a todo sujeito (Lima, 2014a). O duplo, como figura do estranho, que comumente aparece como imagem especular, torna-se causa de desconforto quando o corpo familiar vira objeto de angústia. A experiência do duplo traz à tona a outra cena, provocando um sentimento de estranheza que angustia (Lima, 2014a). Essa transformação da própria imagem corporal por meio dos dispositivos tecnológicos é uma tentativa de preencher esse vácuo produzido pela quebra do espelho na puberdade, recobrindo a imagem do corpo disforme e estranho com outra supostamente perfeita, para se colocar como desejável diante do olhar do outro.

Mas a construção incessante de um corpo supostamente ideal pela via da tecnologia pode ser uma forma de se adiar o encontro com o outro sexo no tempo da puberdade. Se a imagem ideal atrai os rapazes, ela também se torna um impedimento para o encontro corpo a corpo.

Nas conversações, surgiram questões sobre o envio de fotos pessoais para os meninos "famosinhos" da internet que, segundo as adolescentes, se aproveitam da fama para pedir fotos sensuais das meninas. Uma adolescente comenta: "Se o menino for bonito, ele vai receber mais fotos de meninas sem roupa". Ao serem questionadas sobre o motivo do envio dessas fotos aos meninos, uma delas responde: "Ela manda fotos porque confia no cara, porque o ama". À pergunta: "Mostrar o corpo então é uma prova de amor?” ela responde: "Para alguns". Uma adolescente diz: "O cara não 
precisa nem ter intimidade com você para pedir foto pelada". Elas dizem que, apesar da confiança no parceiro, sabem que essa foto "pode cair na rede", ou seja, elas não desconhecem os riscos que correm, entretanto, parecem sentir-se atraídas pela ideia da exposição do corpo na internet. O significante "fama" foi questionado pela psicanalista, levando as jovens a refletirem sobre os significados que elas lhe atribuem.

Nos encontros seguintes, emergiram questões sobre as relações amorosas, seus medos e expectativas. As adolescentes fizeram reflexões sobre amor, traição, confiança, sexo e namoro. Elas ressaltaram a importância de um espaço para falar desses assuntos na escola: "O povo faz reunião para falar de sexo com os pais. Eles não precisam disso, eles já sabem fazer, a gente é que tem que participar".

Com o decorrer dos encontros, as adolescentes falaram sobre a importância da amizade estabelecida entre elas como resultado das conversações: o respeito à opinião de cada uma se estendeu para fora das conversações. Reafirmaram a importância de um espaço de liberdade na escola para se falar de qualquer coisa: "Aqui a gente pode falar de tudo. A gente confia em vocês".

Como um efeito das conversações, destacamos a emergência das diferenças no grupo. Uma adolescente queixou-se do distanciamento da sua mãe, outra falou do controle exagerado do pai, que a vigia pelas redes sociais, enquanto uma adolescente expôs a forma como vivencia as relações amorosas, colocando-se como objeto para os jovens do tráfico, o que despertou a sua angústia e a de outras adolescentes. Duas adolescentes que se colocavam em situações de risco foram encaminhadas para um atendimento individual fora da escola. Esse encaminhamento foi feito em conversa individual com cada uma delas.

A oferta da palavra possibilitou o desinteresse gradativo pela imagem virtual durante as conversações, promovendo a passagem da imagem à palavra. No desenrolar dos significantes, algum saber se constituiu, diminuindo a angústia provocada pelo confronto com o real da puberdade. 


\section{Grupo 2: do discurso do Outro a falar em nome próprio}

Esse grupo foi formado por oito adolescentes entre quatorze e dezesseis anos, três meninas e cinco meninos. Os adolescentes descreveram como usam a internet: para marcar encontros, assistir a filmes de terror, "zoar" pessoas e ter acesso a informações sobre sexualidade. Nas conversações, eles abordaram os seguintes temas: fakes, famosos da internet, segredos na rede, diferenças entre público e privado, "rolezinhos", questões de gênero e adolescência.

Para iniciar as conversações, foram utilizados diversos recursos da internet, como vídeos, fotos, charges, entre outros, relacionados à adolescência e à internet, mas as associações livres permitiram que o assunto inicial tomasse os mais diferentes rumos.

Uma característica marcante desse grupo nos primeiros encontros foi a presença de uma fala que parecia aprisionada ao discurso dos pais. Entretanto, despertados pela emergência do real da puberdade, os adolescentes mostravam que os questionamentos próprios desse tempo lógico começavam a afetá-los. Eles buscavam elaborar as diferenças entre ser criança e ser adolescente, tentando se reconhecer em uma das posições. Alguns se posicionavam mais claramente como crianças, enquanto outros já buscavam elaborar respostas para as questões da adolescência, como o amor, a sexualidade e a separação dos pais.

Inicialmente, eles repetiam os discursos moralizantes dos pais, discorrendo categoricamente sobre o "certo" e o "errado", colocando-se numa posição de alienação ao discurso do Outro: "a internet vicia”, "jogar muito é perigoso", "menina não pode ver isso", "internet só tem coisa ruim”. Os jovens não se implicavam nas situações discutidas e apresentavam pouca espontaneidade em suas falas. $\mathrm{O}$ trabalho realizado com esse grupo caminhou no sentido de que eles pudessem se distanciar do discurso do Outro e construir um discurso próprio. 
Com a emergência da transferência, alguns adolescentes começaram a manifestar suas próprias ideias e interesses no grupo. Passaram a falar dos sites pornô que visitavam, questionando a sexualidade e abordando os medos, as fantasias e as expectativas que a envolvem. No último encontro, eles manifestaram suas opiniões mais livremente. Percebemos que alguns adolescentes do grupo passaram a falar em nome próprio.

A adolescência é uma fase de delicada transição, em que o sujeito deve se separar dos significantes parentais e buscar novos significantes de identificação na cultura. Na nossa sociedade, não há rituais de passagem para o mundo adulto como em outras culturas, de modo que nada informa ao sujeito que a partir de determinado momento ele deve sair de uma posição infantil e assumir uma posição adulta (Le Breton, 2013).

Ela também é um tempo lógico, tempo de compreender a puberdade e, por isso, necessita de um período próprio de elaboração para cada um. Segundo Freud (1910/1996a), esse é um estágio da vida no qual o sujeito tem o direito de se demorar, e isso não lhe pode ser negado. O tempo de assimilação da adolescência é necessário para que o jovem construa uma solução particular aos impasses colocados pela puberdade, podendo então assumir o seu lugar no mundo. Para Rufino (2004), a adolescência é um sintoma social articulado à condição traumática da puberdade que envolve três tempos lógicos: no primeiro, após o transbordamento aflitivo do impacto, resta ao adolescente siderar-se e emudecer; no segundo tempo, o adolescente solicita dos outros, a seu modo, a palavra que lhe falta para nomear o inominável de sua experiência; o terceiro tempo consiste na aventura de se reconstruir, inventando uma resposta inédita às exigências pós-pubertárias. O terceiro tempo consolida a saída da adolescência. Apostamos que o espaço para a palavra é uma condição para a assimilação da adolescência. 


\section{Grupo 3: do ato à palavra}

Esse grupo, formado por sete integrantes (duas meninas e cinco meninos) mostrou-se bastante agitado desde o início, com dificuldades para escutar os colegas. Apesar de serem esclarecidos sobre a proposta do trabalho, todos afirmaram, com exceção de uma menina, que não parecia estar à vontade no grupo, que foram incluídos no grupo porque "são malucos". Alienados ao significante "maluco", designado pelo Outro educacional, eles agiam como tal nas conversações.

No entanto, essa "identidade" à qual se alienavam exercia uma função específica para cada um. Em uma das conversações, Pablo ${ }^{1}$ falou reservadamente com a analista sobre a opressão que sofria por parte de seus pais:

Em casa não posso falar nem contestar meus pais, tenho que acatar tudo que eles falam e ficar quieto, por isso, aqui na escola eu ajo como um maluco. Outro dia, minha mãe veio em uma reunião e foi surpreendida pela coordenadora, que a contestou quando ela disse que eu era um menino quieto e obediente. Aqui na escola sou completamente diferente, não consigo ficar quieto nem calado, preciso extravasar, senão vou morrer. 
Pablo nos mostra que na adolescência o sujeito busca se separar dos significantes parentais que the conferem um lugar no campo do Outro. Essa separação deve ocorrer para que ele "sobreviva" como sujeito, separando-se da posição de objeto. O comportamento rebelde na escola parece ser a forma que ele encontrou de separar-se dos significantes parentais com os quais se identificava. Mas o seu agir pode também denunciar a sua dificuldade em dar um tratamento simbólico ao real da puberdade.

O redespertar das pulsões sexuais após um período de supressão, que Freud (1905/1996b) denominou de "latência", surge como um acontecimento que se impõe ao adolescente; essa irrupção do gozo é vivida por ele com estranheza. As respostas ou saídas encontradas pelos adolescentes diante desse despertar do gozo podem incluir seus atos como uma resposta à angústia decorrente do encontro impossível com o outro sexo e com o real da puberdade (Lacadèe, 2011).

Em O seminário, livro 10 (2005), Lacan aborda as consequências subjetivas da angústia, descrevendo-a como um afeto que designa o encontro com o objeto "a". A angústia sinaliza o encontro com o real que pode desencadear sintomas e inibições, bem como a passagem ao ato e o "acting out", pois o sujeito, afetado por esse encontro, não pensa nem tenta compreender o que se passa com ele: ele simplesmente recorre à ação; age. Por isso, Lacan (2005) considera os atos como uma forma de defesa contra a angústia.

Lacan (2005) traça a distinção entre "acting out" e "passagem ao ato" a partir das elaborações sobre o objeto "a". Esses dois conceitos ganham estatuto propriamente teóricos: enquanto a "passagem ao ato" seria um deixar-se cair ou sair de cena, o "acting out" seria um subir à cena do objeto, agora endereçada ao Outro. Não se trata de situar o sujeito no mesmo lugar que o objeto, mas de situar a interseção vazia deixada pelo objeto no campo do sujeito. Nesse sentido, o "acting out" é uma resposta à angústia desencadeada pelo encontro com o objeto "a", ou 
seja, com a falta que não mais se situa na interseção vazia entre $\mathrm{O}$ sujeito e o Outro.

As questões que surgiram nesse grupo estavam relacionadas às dificuldades enfrentadas por eles nos relacionamentos amorosos que tentavam iniciar por meio das redes sociais ou fora dela. Ao abordarem essas questões, os adolescentes tentavam elaborar a angústia desencadeada pelo encontro com o outro sexo. Não existe um saber prévio que oriente o jovem sobre como agir nesse momento: esse encontro remete o sujeito a um vazio que ele não consegue simbolizar, o que o leva a tentar se mostrar em um agir (Lacadèe, 2011).

Esse ato aparece aqui não só pela via da agitação em sala de aula, mas no teclar insistente e compulsivo nos celulares e nas postagens inconsequentes nas redes, que podem ter efeitos devastadores sobre os sujeitos. Lacan (1993) estabelece uma equivalência entre ato e fala a partir de uma consideração sobre o "acting out". Ele afirma que é preciso "encontrar num ato o seu sentido de palavra" (Lacan, 1993, p. 279). O ato pode ser entendido, pois, como uma mensagem endereçada ao Outro.
Embora o ato, para aquele que o comete, não signifique nada, Lacan (2005) destaca que ele surge como um pedido de ajuda, ainda que velado. $\mathrm{O}$ sujeito se endereça ao Outro para ser escutado em ato. Trata-se, portanto, de uma transferência selvagem, pois não há ato sem Outro. Por isso, cabe àquele que se propõe a escutá-lo acolher o ato do sujeito, elevando-o assim à categoria de uma mensagem, procurando despertar no sujeito um desejo de saber o que está sendo dito por meio do ato.

Acreditamos que o modo como a psicanalista acolheu as atuações dos adolescentes nas conversações possibilitou que eles passassem do ato à palavra, ou seja, que aquilo que era dito em ato fosse verbalizado. Em um dos últimos encontros, um adolescente pediu silêncio aos demais, falou que todos deveriam ficar sentados, conversando, pois aquele era o único espaço em que eles eram escutados. Houve uma mudança a partir desse momento, pois os adolescentes passaram a falar das questões que os angustiavam. Entretanto, na última conversação do semestre, eles retornaram parcialmente com a 
agitação, demonstrando certa dificuldade para encerrar as conversações semanais.

Mas, para além das mudanças coletivas, o nosso interesse reside, especialmente, nos efeitos da oferta da palavra sobre cada sujeito. Maria, uma adolescente do grupo, a princípio se comportava de forma agressiva e viril. No último encontro, Maria perguntou à analista se ela era mãe. Ao obter como resposta um "sim", Maria se surpreendeu. Ela havia se queixado do desinteresse da sua mãe por ela. A transferência que ali se instaurou pôde abrir espaço para o seu questionamento sobre o que é ser mãe e mulher.

Concluímos que esses jovens responderam ao encontro com um real impossível de ser traduzido por meio da identificação com o significante "maluco", ofertado pela escola. As intervenções visaram a diferenciá-los, possibilitando-os a desfazer essa identificação cristalizada e permitindo a cada um construir uma maneira própria de designar aquilo que o perturbava.

Mas, para além das identificações, o buraco aberto pela inexistência da relação sexual desencadeou nos jovens uma resposta pela via do ato. As conversações permitiram o início do tratamento do real pelo simbólico, o que os levou à passagem do ato à palavra.

\section{Grupo 4: da segregação à aceitação da diferença}

Esse grupo foi composto por sete adolescentes de ambos os sexos, na faixa etária entre onze e treze anos. Os participantes, apesar de apresentarem certa agitação, mostraram-se participativos, trazendo suas experiências, seus interesses e suas dificuldades em relação ao tema.

No trabalho de conversação, mesmo que exista um tema ou uma questão que norteie os encontros, não é possível prever o porvir, pois cada grupo é único e, ao mesmo tempo, 
diversificado, constituído pela singularidade de cada um. Nesse grupo, especialmente, o que nos chamou a atenção foi a dificuldade dos adolescentes em lidar com a diferença, encarnada na presença de Alberto.

Alberto, desde o primeiro dia, apresentou sua diferença. Sentava-se afastado do grupo e, de cabeça baixa, não tirava os olhos do celular. Quando era convocado a falar, respondia sempre algo considerado pelo grupo como sem sentido. Por exemplo, quando perguntado sobre o que gostava de fazer na internet, ele respondeu: "cocô". Suas respostas, frequentemente de conteúdo chulo, causavam certa revolta na turma: "Tá vendo, é louco mesmo" ou "manda esse menino calar a boca". A função do analista na conversação não é interpretar, mas fazer cada participante tomar a palavra e permitir que o grupo possa se escutar. Assim, a intervenção da analista foi sempre no sentido de incluir Alberto e relativizar sua fala: "Nossa, cocô? Mas será que não tem outra coisa que você faz na internet, não?”. Ele respondeu: "Eu também jogo", ao que a turma completa: "Ele é viciadão".

Ainda que grande parte do grupo usasse o celular durante a conversação, a dificuldade de Alberto em largar o aparelho deixava os outros componentes irritados. Eles insistiam que a analista interviesse da mesma forma que a escola: "Toma o celular dele! Você não sabe? Aqui não pode usar celular, você tem que tomar!", esbravejava a colega Regina. Nesses momentos, retomávamos o que havia sido explicado no primeiro encontro, ou seja, que apesar de estar inserida no ambiente escolar, a conversação era uma atividade diferente das outras, uma atividade não pedagógica, e que era muito importante respeitarmos o outro. Também foi perguntado a Alberto se ele se sentia capaz de guardar o celular por alguns instantes, pois a sua participação era considerada importante. Foi deixado claro que não era uma imposição, mas que seria bom se ele pudesse deixar o celular por alguns instantes, pois estávamos interessados em escutar a sua opinião sobre o tema do dia: a fama na internet. Ele então disse que para ter fama na internet é só fazer algum vídeo que mostre "puta, piroca e dinheiro". Os colegas, nesse momento, concordaram com ele: "Pior que é isso aí mesmo". 
A ciência, ao introduzir a universalização, tem efeitos sobre cada um e sobre os grupos sociais. O discurso da ciência tende a anular as particularidades do sujeito em função de um quantificador universal (Miller, 2010). A escola, muitas vezes, compartilha esse discurso universalizante, atribuindo aos sujeitos que não se enquadram nessa lógica significantes como "hiperativos", "agitados", "sem limites" etc. Essa tendência à universalização leva à segregação das diferenças.

Para Bauman, "Selecionar, identificar e excluir a 'margem da normalidade' é um resultado necessário do processo de construção da ordem e um custo inevitável de sua perpetuação" (2013, p. 72). Assim se constitui uma maioria e uma minoria, e tal minoria torna-se facilmente identificável e consequentemente desvalorizada como um desvio marginal. Como conclusão, cria-se uma anormalidade em oposição a uma normalidade que servirá como sustentáculo para uma suposta ordem social.

Mas o que a psicanálise tem a dizer sobre o fenômeno da segregação? Laurent (2014) adverte que, para Lacan, a segregação, mesmo sendo um fenômeno social presente em todas as culturas, muda seus objetos à medida que as formas de organização social se modificam. Ela sempre se aloja na recusa de um gozo inassimilável. A lógica desenvolvida por Lacan se sustenta no fato de que não sabemos com qual gozo nos orientamos. A única coisa que sabemos é rechaçar o gozo do Outro. Assim, a segregação consiste em separar um grupo classificando-o por seu modo de gozo, seja ele o grupo dos judeus, negros, homossexuais ou "loucos" (Najles, 2014).

Como a segregação é vivida na atualidade? O discurso da ciência e o discurso do capitalismo se situam no nível do universal, com a máxima “tudo para todos". Entretanto, no nível da singularidade, não se suporta o gozo do Outro. O que está em questão é a tolerância ou intolerância ao gozo do Outro. O problema não se encontra na constatação da diferença, mas na sua segregação. O que tentamos fazer no trabalho de conversação com esses adolescentes foi demonstrar que o modo 
de gozo de um não é o modo de gozo do outro, e isso não constitui nenhum problema.

Assim, Alberto foi, aos poucos, se aproximando. Ele procurava sentar-se ao lado da analista e contribuía com algumas falas. Muitas vezes, ele ainda era "zoado" pelos colegas e ria disso. Um dia, o grupo propôs que levássemos o computador para que eles pudessem mostrar os jogos dos quais haviam falado. Nesse dia, Alberto disse: “Quero jogar”, mas um dos garotos não conseguia passar a vez. A intervenção da analista não foi necessária. Um colega disse: "Larga esse computador, véi! Não tá vendo que é a vez do Alberto, não? Ele já falou que quer jogar...”. Sua habilidade nos jogos foi reconhecida pelo grupo: “Ele é muito bom, véi! Olha lá!”.

No último encontro, houve uma festa organizada pelos adolescentes. Alberto, nesse dia, não se sentou em seu lugar cativo ao lado da analista, mas se posicionou ao lado de Regina. Num primeiro momento, ele se esticou para pegar um cajuzinho, mas depois se intimidou e ficou parado, sentado, sem falar nada. Regina percebeu a dificuldade do colega e passou a ajudá-lo. Arrastava os docinhos discretamente para que eles chegassem até Alberto, que então os comia. Ela o fez repetidas vezes, levando sempre um cajuzinho para ele, até que lhe entregou o último doce.

Regina e a amiga Bianca resolveram, então, fazer um funk para o grupo. Elas disseram: "Peraí que a gente vai ali fora fazer um funk. Como é que chama isso aqui mesmo, redes virtuais?". De volta à sala elas cantaram: "Aqui, nas redes virtuais, tá rolando uma festinha. Vem com as MCs. Vem com a Juju. Vem com a Nayara. Vem com o bonde todo!".

E foi com esse convite que elas concluíram o trabalho de conversação: um convite a suportar a diferença no outro, e que, acreditamos, foi aceito pelo "bonde todo".

\section{Considerações finais}

O desinteresse pelo saber escolar na época atual contrasta com o grande interesse dos adolescentes pelos dispositivos 
tecnológicos. Para Bloj (2011), o acesso à internet reclama a produção de modos particulares de organização do universo escolar. Além disso, as tecnologias digitais acabam por ocupar o lugar vazio instaurado pela ausência do Outro (Lima, 2014b). Esse interesse pode caminhar para uma dependência virtual como mais uma droga que o mercado oferece para o gozo imediato, quando a tela do computador passa a se ocupar dessa infância e adolescência negligenciadas. A tela esconde o fato de que, sob a oferta, há uma demanda. O objeto do gozo é a própria criança ou o adolescente (Laurent, 2013).

As crianças e os adolescentes se tornam objetos de vigilância dos pais e da sociedade na cultura atual. Com um celular sempre à mão, a criança e o adolescente se tornam um aparelho de controle dos pais. Por sua vez, as escolas reforçam a vigilância sobre os alunos, instalando câmeras por todo o ambiente escolar. Da mesma forma que eles são vigiados, os adolescentes vigiam todos, fotografando e filmando colegas e professores e publicando as suas fotos e vídeos nas redes sociais. Assim, todos passam a ser vigiados e controlados. Mas o controle da infância e da adolescência fracassa. Tanto os dispositivos tecnológicos quanto as políticas segregativas classificatórias falham. Pela via do sintoma, o sujeito encontra uma saída ao controle do Outro. Os sintomas escolares denunciam a constatação feita pelos adolescentes da impossibilidade do discurso do mestre em responder às suas questões (Cunha \& Lima, 2013). Assim, manifesta-se o mal-estar na educação. Fica-nos a questão sobre os modos de "fazer da educação um instrumento que torne mais digna a sustentação do mal-estar na civilização" (Kupfer, 2007, p. 148).

O psicanalista está atento às formas de manifestação do mal-estar na contemporaneidade e aos recursos que o sujeito cria para se fazer ouvir. Para Brisset (2013), a conversação é um dispositivo em condição de abrir intervalos para se respirar, para fazer falar as desordens, dificuldades e urgências trazidas pelos adolescentes, mediante atos e sintomas. Os adolescentes nos indicam as saídas que eles constroem para lidar com os desafios atuais. 
Na solidão de cada um, os jovens tentam se arranjar com o resto que não faz laço social. As conversações visam a acolher o que a escola tenta extinguir, a dimensão ineducável do sujeito. Apostamos que o real impossível pode, pela via de uma contingência, abrir novas possibilidades de escrever-se.

PSYCHOANALYSIS, EDUCATION AND VIRTUAL SOCLAL NETWORKS: LISTENING ADOLESCENTS IN SCHOOL

\begin{abstract}
The interest and concern regarding the use of technological devices by adolescents is growing every day. The social networks of the internet have been used by adolescents not only for communication, but also for social segregation. This study analyzes the results of a research intervention carried out in a public school whose subject was the use of social networks by adolescents. For this, it was used a psychoanalytic conversational methodology with four groups of adolescents. It was observed a specific process for each group and the effects of conversations on each subject.
\end{abstract}

Index terms: adolescents; social networks; school.

\title{
EL PSICOANÁLISIS, LA EDUCACIÓN Y LAS REDES SOCIALES VTRTUALES: ESCUCHAR LOS ADOLESCENTES EN LA ESCUELA
}

\section{RESUMEN}

El interés y la preocupación por el uso que los adolescentes hacen de los dispositivos tecnológicos son más visibles cada día. Las redes sociales de Internet son utilizadas por los jóvenes no solo para la comunicación, sino también para la segregación social. En este estudio se analizan los resultados de la investigación y la intervención llevada a cabo en una escuela pública cuyo tema fue el uso de las redes sociales por los jóvenes. Para ello, se utilizó la metodología de conversación psicoanalítica con cuatro grupos de adolescentes. Deducimos un proceso específico para cada grupo, además de los efectos de las conversaciones sobre cada sujeto.

Palabras clave: adolescentes; redes sociales; escuela.

\section{REFERÊNCIAS}

Bauman, Z. (2013). Sobre educação e juventude. Rio de Janeiro: Jorge Zahar.

Bloj, A. (2011). Educação, cidadania e subjetividade. In L. Mrech, M. Rahme, \& M. R. Pereira (Orgs.), Psicanálise, educação e diversidade (pp. 41-50). Belo Horizonte, MG: Fino Traço/FAPEMIG.

Brisset, F. O. (2013). Apresentação. In F. O. Brisset, A. L. Santiago, \& J. Miller (Orgs.), Crianças falam! E tem o que dizer. Experiências do CIEN no Brasil. Belo Horizonte, MG: Scriptum.

Cunha, C. F., \& Lima, N. L. (2013). A escuta de adolescentes na escola: a sexualidade como um sintoma escolar. Estilos da Clinica, 18(3), 508-517. doi: http://dx.doi. org/10.11606/issn.1981-1624.v18i3p508-517. 
Freud, S. (1996a). Breves escritos: contribuiçôes para uma discussão acerca do suicídio. In S. Freud, Edição standard brasileira das obras psicológicas completas de Sigmund Freud. (J. Salomão, trad., Vol. 11, pp. 217218.). Rio de Janeiro, RJ: Imago. (Trabalho original publicado em 1910)

Freud, S. (1996b). Três ensaios sobre a teoria da sexualidade. In S. Freud, Edição standard brasileira das obras psicológicas completas de Sigmund Freud. (J. Salomão, trad., Vol. 7, pp. 129-238). Rio de Janeiro: Imago. (Trabalho original publicado em 1905)

Kupfer. M.C. (2007). Educação para o futuro. São Paulo, SP: Escuta.

Lacan, J. (2005). Passagem ao ato e acting out. In J. Lacan, $O$ seminário, livro 10: a angústia, 1962-1963 (pp. 128-145). Rio de Janeiro, RJ: Jorge Zahar.

Lacan, J. (1993). A função criativa da palavra. In J. Lacan, $O$ seminário, livro 1: os escritos técnicos de Freud, 1953-1954 (pp. 269279). Rio de Janeiro, RJ: Jorge Zahar.

Lacadèe, P., \& Monier, F. (Orgs.). (2000). Le pari de la conversation. Paris: Institut du Champs Freudien/Centre interdisciplinaire sur l'Enfant (CIEN).

Lacadèe, P. (2007). A passagem ao ato na adolescência. Revista Asephallus, 2(4). Recuperado de http://www.isepol.com/ asephallus/numero_04/traducao_02.htm.

Lacadèe, P. (2011). O despertar e o exilio: ensinamentos psicanalíticos da mais delicada das transiçōes, a adolescência. Rio de Janeiro, RJ: Contra Capa Livraria.

Laurent, E. (2013). A crise do controle da infância. In F. O. Brisset, A. L. Santiago, \& J. Miller (Orgs.), Crianças falam! E tem o que dizer. Experiências do CIEN no Brasil. Belo Horizonte, MG: Scriptum.

Laurent, E. (2014). Le racisme 2.0. Lacan Quotidien, 371. Recuperado de http:// www.lacanquotidien.fr/blog/wp-content/ uploads/2014/01/LQ-371.pdf.

Le Breton, D. (2003). Adeus ao corpo: antropologia e sociedade (M. Appenzeller trad.). Campinas, SP: Papirus. 
Le Breton, D. (2013). Une brève histoire de l'adolescence. Paris, França: J. C. Béhar. Lima, N. L. (2014a). A escrita virtual na adolescência: uma leitura psicanalítica. Belo Horizonte, MG: UFMG.

Lima, N. L. (2014b). Da lei edipiana à norma entre pares: as identificaçóes nas redes sociais da internet. In T. C. Santos, J. Santiago, \& A. Martello (Orgs.), Os corpos falantes e a normatividade do supersocial (pp. 109-136). Rio de Janeiro, RJ: Cia de Freud.

Lima, N. L., \& Rezende, A. O. (2013). O poder normativo nas escolas e seus efeitos sobre os sujeitos. Estilos da Clínica, 18(1). doi: http://dx.doi.org/10.11606/ issn.1981-1624.v18i1p34-52

Miller, J. A. (2010). Extimidad. Buenos Aires, Argentina: Paidós.

Miller, J. A. (2010). A prática da conversação. In J. A. Miller, Conferencias porteñas (Tomo 3). Buenos Aires, Argentina: Paidós.

Najles, A. R. (2014). Delicias de la intimidad: de la extimidad al sinthome. Buenos Aires, Argentina: Grama.

Ruffino, R. (2004). A condição traumática da puberdade na contemporaneidade e a adolescência como sintoma social a ela articulada. Textura: Revista de Psicanálise, 4(4), 1-12. Recuperado de http://www.revistatextura.com/leia/aconditraumatica. pdf

Santiago, A. L. (2008). O mal-estar na educaçáo e a conversaçáo como metodologia de pesquisa intervençáo na área de psicanálise e educação. In L. R. Castro, \& V. Besset. (Orgs.), Pesquisa-intervenção na infância e adolescência (pp. 113-131). Rio de Janeiro, RJ: NAU/FAPERJ.

\section{NO'TA}

1. Utilizamos nomes fictícios para resguardar o anonimato dos adolescentes participantes das conversaçôes.

nadia.laguardia@gmail.com nayaraserrano@hotmail.com jutassara@hotmail.com karinacasula@hotmail.com luizapinheiro@yahoo.com.br ellenrose.psi@gmail.com karinanihari@gmail.com mirabellaferraz@gmail.com soaresmarina@ig.com.br

Av. Antônio Carlos, 6627 31270-901 - Belo Horizonte-MG - Brasil. 